\title{
MN1/ETV6 Fusion Protein
}

National Cancer Institute

\section{Source}

National Cancer Institute. MN1/ETVG Fusion Protein. NCI Thesaurus. Code C99316.

A fusion protein encoded by the MN1/ETV6 fusion gene. This protein is comprised of most of the probable tumor suppressor protein MN1 fused with the C-terminal ETS DNA binding domain of the transcription factor ETV6 protein. 